Research Paper

\title{
Interaction of antimicrobial peptide Plantaricin149a and four analogs with lipid bilayers and bacterial membranes
}

\author{
José Luiz de Souza Lopes ${ }^{1}$, Denise Cavalcante Hissa ${ }^{2}$, Vânia Maria Maciel Melo², \\ Leila Maria Beltramini ${ }^{1}$ \\ ${ }^{1}$ Grupo de Biofísica Molecular "Sérgio Mascarenhas", Instituto de Física de São Carlos, \\ Universidade de São Paulo, São Carlos, SP, Brazil. \\ ${ }^{2}$ Departamento de Biologia, Universidade Federal do Ceará, Fortaleza, CE, Brazil.
}

Submitted: January 23, 2012; Approved: April 4, 2013.

\begin{abstract}
The amidated analog of Plantaricin149, an antimicrobial peptide from Lactobacillus plantarum NRIC 149, directly interacts with negatively charged liposomes and bacterial membranes, leading to their lysis. In this study, four Pln149-analogs were synthesized with different hydrophobic groups at their N-terminus with the goal of evaluating the effect of the modifications at this region in the peptide's antimicrobial properties. The interaction of these peptides with membrane models, surface activity, their hemolytic effect on red blood cells, and antibacterial activity against microorganisms were evaluated. The analogs presented similar action of Plantaricin149a; three of them with no hemolytic effect $(<5 \%)$ until $0.5 \mathrm{mM}$, in addition to the induction of a helical element when binding to negative liposomes. The $\mathrm{N}$-terminus difference between the analogs and Plantaricin149a retained the antibacterial effect on S. aureus and P. aeruginosa for all peptides ( $\mathrm{MIC}_{50}$ of $19 \mu \mathrm{M}$ and $155 \mu \mathrm{M}$ to Plantaricin149a, respectively) but resulted in a different mechanism of action against the microorganisms, that was bactericidal for Plantaricin149a and bacteriostatic for the analogs. This difference was confirmed by a reduction in leakage action for the analogs. The lytic activity of Plantaricin149a is suggested to be a result of the peptide-lipid interactions from the amphipathic helix and the hydrophobic residues at the $\mathrm{N}$-terminus of the antimicrobial peptide.
\end{abstract}

Key words: antimicrobial activity; antimicrobial peptide; calcein leakage, hemolytic assay.

\section{Introduction}

It is increasingly common to find strains of pathogens which are antibiotic resistant, and some of them are resistant to many antibiotics and chemotherapeutic agents (Nikaido, 2009). This phenomenon of multidrug resistance in bacteria has led to the development of new antibiotics, to the modification of the existing drugs, and to the use of two or more of the available antibiotics in association to deal with the resistant strains (Toke, 2005; Nikaido, 2009).

As an alternative to this process (Marshall and Arenas, 2003), antimicrobial peptides (AMPs) represent a promising class of compounds that were shown to maximize their inhibitory activity against pathogenic microorganisms by the manipulation of this chemical structure, since it is possible to introduce different modifications on their primary structure, like amidation, cyclation and insertion of non-proteic groups on their N-terminal end (Boman, 1995; Tsuberya et al., 2001; Gordon and Romanowski, 2005; Gong et al., 2011).

Lactic acid bacteria (LAB) are currently exploited as a reservoir of AMPs which present potential technological applications (McKay and Baldwin, 1990; Zavisic et al., 2012). Plantaricin 149 (Pln149, YSLQMGATAIKQVKK LFKKKGG) is a naturally occurring 22 -amino acid peptide, isolated from Lactobacillus plantarum NRIC149 (Kato et al., 1994). Its synthetic amidated analog, Pln149a, is a positively charged linear peptide with a narrow spectrum towards Staphylococcus aureus and Listeria monocytogenes that undergoes a typical helical induction in a

Send correspondence to L.M. Beltramini. Grupo de Biofísica Molecular "Sérgio Mascarenhas", Departamento de Física e Informática, Instituto de Física de São Carlos, Universidade de São Paulo, Av. Trabalhador São-carlense 400, São Carlos, SP, Brazil. E-mail: leila@ifsc.usp.br. 
non-polar environment or when it interacts with negative biomembranes (Muller et al., 2007). The action of Pln149a against Saccharomyces cerevisae was also established, showing the peptide causes morphological changes on the yeast cell, due to its interaction with the membrane, followed by its disruption (Lopes et al., 2009).

The mechanism of action proposed for Pln149a is an electrostatic attraction of the disordered peptide in the bulk solution to the charged phospholipids in the membrane that induces an amphipathic $\alpha$-helix in the peptide structure and its accumulation on the phospholipid surface. The amphipathic helix stretches from residue Ala7 to Lys20, creating a polar side with 5 Lys residues that enables interactions, and a non-polar side, due to its hydrophobic residues (Ala, Leu, Ile, Phe, Val) that lead the Van de Waals contributions. At this stage, it was suggested that the peptide must remain associated with the negatively phospholipids, and its N- terminal residues are introduced in the phospholipids acyl chains, gradually altering the surface packing of the lipid layer and resulting in the membrane disruption (Lopes et al., 2009).

According to this mechanism, it can be proposed that the positive region of $\mathrm{P} \ln 149 \mathrm{a}$ itself is likely to trigger its antibacterial activity, since the helix stabilization represents a fundamental/essential step for the peptide-membrane binding. In addition, it was demonstrated for the antimicrobial peptide PlantaricinA (Kristiansen et al., 2005) that the pentapeptide YSLQM, the same from the N-terminus sequence of Pln149a, does not present significant antibacterial properties. However, the assumption that the N-terminus of Pln149a must be located in a non-polar environment in the bacterial membrane suggests its participation in the peptide's antimicrobial property.

In the present work, to study this assumption, four other Pln149a analogs were synthesized; their antimicrobial and hemolytic activities and the interactions with biomembrane models were investigated. The four analogs retained the inhibitory activity against Pseudomonas aeruginosa and Staphylococcus aureus growth but with a different mechanism of action presented for Pln149a, suggesting the importance of the N-terminus in the lytic property of the antimicrobial peptide.

\section{Materials and Methods}

\section{Materials}

Chemicals were purchased from Sigma-Aldrich (St. Louis, USA), unless stated. All protected amino acids, coupling reagents and polymers were obtained from NovaBiochem (San Diego, USA). Solvents were of P.A. grade and buffers were prepared in MilliQ water and filtered in $0.2 \mu \mathrm{m}$ polycarbonate membranes.

\section{Peptide synthesis and purification}

Pln149a was synthesized by the Fmoc strategy and purified by Reverse Phase Chromatography as described elsewhere (Lopes et al., 2009). The four new Pln149a analogs were synthesized with the peptide size reduced by the removal of the first $5 \mathrm{~N}$-terminus residues of the Pln149a primary structure, resulting in residue 6 to 22 of Pln149a. In addition to this 17 -amino acid peptide, three different $\mathrm{N}$-terminus modifications were introduced on the synthetic analogs: a short hydrocarbon chain (acetyl group), that was coupled an the $\mathrm{N}$-terminus by the addition of acetic anhydride 20\% in DMF (dimethylformamide) for $5 \mathrm{~min}$ in the peptidyl-resin, followed by $100 \mu \mathrm{L}$ DIEA (diisopropylethylamine) for $30 \mathrm{~min}$ incubation; a longer hydrocarbon chain (N-octyl group), that was added by mixing octanoic acid in DMF (1:1), followed by the addition of DIEA, HOBt (Hydroxybenzotriazole) and PyBOP (benzotriazol-1-yl-oxytripyrrolidinophosphonium

hexafluorophosphate) according to the resin capacity, for 2 hours of incubation; and the Fmoc group of the last amino acid residue coupled, that was retained at the peptide N-terminus.

After the incorporation of all amino acid residues and modifications, the peptides were cleaved with a mixture of trifluoroacetic acid (TFA): triisopropylsilane (TIS): $\mathrm{H}_{2} \mathrm{O}$ (95: 2.5:2.5, v/v) for $3 \mathrm{~h}$. The crude peptides were precipitated with cold diethyl ether, centrifuged at $700 \mathrm{~g}$ for $5 \mathrm{~min}$ and lyophilized. The four Pln149-analogs were named as Pln149(6-22), for the 17-amino acid peptide; AcPln149(6-22), for the acetylated analog; Noctyl-Pln149(622), and Fmoc-Pln149(6-22).

Aliquots of each analog peptide were purified by reverse-phase chromatography using a GE ÄKTA Purifier System (GE Healthcare) with an YMC-Pack Polymer $\mathrm{C}_{18}$ column ( 250 x $4.6 \mathrm{~mm}, 6 \mu \mathrm{m}$ bead size, Waters, Germany) equilibrated with $0.1 \%$ (v/v) TFA/water (solvent A). Elution was performed at a $1 \mathrm{~mL} / \mathrm{min}$ flow rate using a twostep gradient: initially, from $0 \%$ to $70 \%$ solvent $\mathrm{B}$ (acetonitrile $90 \%$ in water containing $0.1 \%$ TFA) over $40 \mathrm{~min}$, followed by $70-100 \%$ of the same solvent over $1 \mathrm{~min}$. Absorbance was monitored at $220 \mathrm{~nm}$ and the fractions of each peptide were collected and lyophilized.

\section{Peptide characterization}

Mass Spectrometry analyses of Pln149a and all the modified-analogs were performed with electrospray ionization with a Quattro II electrospray triple quadrupole spectrometer (Micromass, Manchester, UK) on positive mode. Aliquots of each peptide $(0.02 \mathrm{mg} / \mathrm{mL})$ were prepared in a mixture of $60 / 0.5 / 39.5$ of methanol/formic $\mathrm{acid} /$ water as the mobile flow phase, and further directly injected in the spectrometer with a $10 \mu \mathrm{L}$ loop. Experiments were performed by scanning from a 1000 to $2000 \mathrm{~m} / \mathrm{z}$ ratio.

To check the primary structure of the purified Pln149(6-22), automated Edman degradation was performed on an automatic protein sequencer PPSQ-23A Shimadzu (Kyoto, Japan). 


\section{Circular dichroism (CD) analysis}

The CD spectra of Pln149a and analog peptides were recorded on a Jasco J-815 CD spectrometer (Tokyo, Japan) from 190 to $250 \mathrm{~nm}$, using a $0.1 \mathrm{~cm}$ path length rectangular quartz cuvette, at $25^{\circ} \mathrm{C}$. For each spectrum, the data from 8 scans were averaged and the reference spectrum was subtracted. Peptides were measured $(0.15 \mathrm{mg} / \mathrm{mL})$ in water and in the presence of $1 \mathrm{mM}$ of large unilamellar vesicles (LUVs) of palmitoyl-oleoyl phosphatidyl glycerol (POPG), a negatively charged vesicle, and of palmitoyloleoyl phosphatidyl choline (POPC), a zwitterionic phospholipid vesicle, prepared as described elsewhere (Lopes et al., 2009).

\section{Hemolytic activity against human erythrocytes}

The present method was based on Castro et al. (2009). Briefly, aliquots $(100 \mu \mathrm{L})$ of $1 \%(\mathrm{v} / \mathrm{v})$ suspension human erythrocytes in $20 \mathrm{mM}$ Sodium Phosphate buffer (pH 7.4) containing $150 \mathrm{mM} \mathrm{NaCl}$ were employed to determine the hemolytic effect of Pln149a and analog peptides in serial dilutions ( 1 to $500 \mu \mathrm{M})$. Samples were incubated for $1 \mathrm{~h}$ at $37^{\circ} \mathrm{C}$, centrifuged at $3000 \mathrm{~g}$. The supernatant was transferred to a 96-well microplate and evaluated spectrophotometrically at $405 \mathrm{~nm}$ to monitor the release of hemoglobin. Triton X-100 was used as control of $100 \%$ lysis, and hemolysis percentage was calculated using the Eq. (1):

$$
\%_{\text {hemolisis }}=\frac{\left[A_{\text {Peptide }}-A_{P B S}\right]}{\left[A_{\text {Triton }}-A_{P B S}\right]}
$$

\section{Antimicrobial activity and MIC determination}

To study antibacterial activity of Pln149a and analogs, microtiter broth growth inhibition assays were conducted with the reference strains of Staphylococcus aureus ATCC 25923 and Pseudomonas aeruginosa ATCC 9027, based on the method described elsewhere (Wayne, 1999), with some modifications.

The bacteria were firstly grown in Mueller-Hinton broth $(5 \mathrm{~mL})$ at $37^{\circ} \mathrm{C}$. When $\mathrm{OD}_{600 \mathrm{~nm}}$ reached 1.0 , the bacterial suspension was diluted in fresh Mueller-Hinton broth and adjusted to $\mathrm{OD}_{600 \mathrm{~mm}} 0.010\left(10^{6} \mathrm{UFC} / \mathrm{mL}\right)$. Growth inhibition assays were carried out by adding sterile Pln149a $(100 \mu \mathrm{L})$ and each of the four derived peptides in PBS $(\mathrm{pH}$ 7.4) to a 96-well microtiter plate. Serial dilutions of the peptides (620 to $1.2 \mu \mathrm{M})$ were incubated with the diluted bacterial suspension 1:1 (v/v) in Mueller-Hinton broth. A positive control was used to incubate the bacterial suspension with PBS and a negative control containing $0.4 \%(\mathrm{v} / \mathrm{v})$ formaldehyde. Each microplate was incubated for $24 \mathrm{~h}$, at $37^{\circ} \mathrm{C}$ and growth inhibition was analyzed at $600 \mathrm{~nm}$ on a Microplate TP-reader (Thermoplate). Minimal inhibitory concentration $\left(\mathrm{MIC}_{50}\right)$ was considered the lowest concentration that inhibits $50 \%$ bacterial growth. All experiments were performed in duplicate.
Additionally, to verify if the peptides action was either bactericidal or bacteriostactic, aliquots $(5 \mu \mathrm{L})$ of each well from the microplate were subcultived in a Petri plate with Mueller-Hinton agar. The plates were incubated at $37^{\circ} \mathrm{C}$ for $24 \mathrm{~h}$ and growth was visually detected.

The same assay was conducted with the Pln149peptides to study their antifungal activity against Candida albicans, using the Brain Heart Infusion (BHI) medium.

\section{Calcein leakage}

To study the action of peptides to promote the calcein leakage from the vesicles internal compartment, LUVs of POPG (1-palmitoyl-2-oleoyl-sn-glycero-3-phospho-racglycerol) with entrapped calcein were prepared by hydrating a dried lipid film with $35 \mathrm{mM}$ calcein in Hepes $10 \mathrm{mM}$ buffer (pH 7.4), followed by a 10 freeze-thaw cycles and extrusion through a $100 \mathrm{~nm}$ membrane. Untrapped calcein was separated from the LUVs by size exclusion chromatography on a Sephadex- $G 65$ column, and liposomes concentration was determined by McClare assays (McClare, 1971). The release of calcein from the LUVs was monitored by adding increasing concentrations of each Pln149 analog peptide $(0.25$ to $4.0 \mu \mathrm{M})$ to LUVs $(0.1 \mathrm{mM})$ in a quartz rectangular cuvette under agitation. Fluorescence was measured at $520 \mathrm{~nm}$ on an ISS K2 spectrofluorimeter (ISS Fluorescence, Analytical and Biomedical Instruments) with excitation at $490 \mathrm{~nm}$ for 15 min incubation at $25^{\circ} \mathrm{C}$. The percent leakage was determined according to the Eq. (2):

$$
\%_{\text {Leakage }}=\frac{\left[F-F_{0}\right]}{\left[F_{\max }-F_{0}\right]} \times 100
$$

where the maximum fluorescence intensity $\left(F_{\max }\right)$ was determined by adding a solution of $10 \%(\mathrm{w} / \mathrm{v})$ Triton X-100 to the cuvette, $F_{0}$ represents the initial fluorescence intensity of the intact vesicle, and $F$, the intensity after $15 \mathrm{~min}$ incubation with each peptide.

\section{Results}

\section{Peptide synthesis, purification and characterization}

Pln149a and other four analog peptides were synthesized by solid phase method using the Fmoc chemistry. A manual synthesis was successfully performed to yield a peptide corresponding to Pln149a from residue 6 to 22 . At this step, the peptidyl-resin was equally subdivided in four parts to generate each Pln149 reduced analog. The first one was cleaved from the resin with no N-terminus insertions, resulting in the analog Pln149(6-22). Three different groups were attached to the N-terminal residue of peptidyl-resin: an acetyl, an N-octyl, and a hydrophobic moiety Fmoc, resulting in the three Pln149 analogs with N-terminus modifications: Ac-Pln149(6-22), Noctyl-Pln149(622) and Fmoc-Pln149(6-22), respectively. The primary 
structure (checked by Edman degradation), and molecular weight (determined by electrospray mass spectrometry) of each analog are in Table 1.

The four modified peptides were purified to homogeneity (> 98\%) by HPLC. The purification chromatogram profile, showed in Figure 1, revealed the efficiency of man- ual synthesis due to the major peak of each analog and the increase in hydrophobicity in the peptides, in which the analog Pln149(6-22) was eluted at 32\% of acetonitrile, and the other-analogs containing the acetyl, the N-octyl and the Fmoc groups were eluted at positions corresponding to a 43,55 , and $59 \%$ of acetonitrile, respectively.


Figure 1 - Reverse-Phase Chromatography profile of Pln149a analog peptides. (A) Pln149(6-22), (B) Ac-Pln149(6-22), (C) Noctyl-Pln149(6-22), (D) Fmoc-Pln149(6-22) on $\mathrm{C}_{18}$ column correspond to the major peak. Column was equilibrated with $\mathrm{H}_{2} \mathrm{O}$ (TFA $0.1 \%$ ) and eluted in a gradient of acetonitrile $90 \%$ (TFA $0.1 \%$ ) over $40 \mathrm{~min}$ (dotted curves), in a $1 \mathrm{~mL} / \mathrm{min}$ flow rate. The difference in hydrophobicity is a result of the peptide size reduction and the N-terminal modifications.

Table 1 - Primary structure, molecular weight, MIC and Minimum bactericidal concentration (MBC) of Pln149a and analogs.

\begin{tabular}{|c|c|c|c|c|c|c|c|c|}
\hline \multirow[b]{2}{*}{ Peptide } & \multirow[b]{2}{*}{ Sequence } & \multirow[b]{2}{*}{$\mathrm{MW}(\mathrm{Da})^{*}$} & \multicolumn{3}{|c|}{ S. aureus } & \multicolumn{3}{|c|}{ P. aeruginosa } \\
\hline & & & MIC & MIC50 & MBC & MIC & MIC50 & MBC \\
\hline$P \ln 149 a$ & YSLQMGATAIKQVKKLFKKKGG & 2423.7 & 78 & 19 & 78 & 310 & 155 & 310 \\
\hline$P \ln 149(6-22)$ & GATAIKQVKKLFKKKGG & 1801.3 & 310 & 78 & $>620$ & 310 & 155 & $>620$ \\
\hline Ac-Pln149(6-22) & Acetyl-GATAIKQVKKLFKKKGG & 1843.3 & 310 & 78 & $>620$ & 310 & 155 & $>620$ \\
\hline Noctyl-Pln149(6-22) & N-octyl-GATAIKQVKKLFKKKGG & 1928.5 & 10 & 10 & 310 & 620 & 155 & $>620$ \\
\hline Fmoc-Pln149(6-22) & Fmoc-GATAIKQVKKLFKKKGG & 2023.5 & 38 & 38 & 155 & 78 & 19 & 155 \\
\hline
\end{tabular}

Values are given in $\mu \mathrm{M}$.

*MW, molecular weight determined by mass spectrometry. 


\section{Circular dichroism (CD) studies}

The CD spectra of all the analogs peptides in water were similar to the Pln149a CD spectrum (9) and to the linear antimicrobial peptides in aqueous solution (Tsuberya et al., 2001; Koo et al., 2008; Leite et al., 2008; Castro et al., 2009), as showed in Figure 2A. These spectra are typical of disordered secondary structure in a polypeptide chain, with minima centered at $198 \mathrm{~nm}$ region.

The CD spectrum of each peptide was not altered when in the presence of the zwitterionic vesicles of POPC (data not shown). However, a significant conformational change in the presence of the negatively charged vesicles (POPG) was observed (Figure 2B), with the induction of a helical element on its secondary structure, with minima at 222 and $208 \mathrm{~nm}$ and a maximum centered at $196 \mathrm{~nm}$ (Lopes et al., 2009). This behavior is observed for cationic linear helical antimicrobial peptides when in the presence of negative biomembrane models (Yeaman and Yount, 2003; Sato and Feix, 2006; Zhao et al., 2006).

\section{Hemolytic assay}

In this assay, hemolysis was visually detected in positive control right after the addition of $1 \%(\mathrm{v} / \mathrm{v})$ Triton $\mathrm{X}-100$, and sedimentation was observed for the negative control (PBS). Cell sedimentation was observed for the wells corresponding to $\mathrm{P} \ln 149$ analogs in the range from 1 to $500 \mu \mathrm{M}$, indicating no hemolytic activity (less than $5 \%$ ) for Pln149(6-22), Ac-Pln149(6-22), and Noctyl-Pln149(622), data not shown. The analog Fmoc-Pln149(6-22) presented different behavior: weak hemolytic activity was observed at concentrations below $125 \mu \mathrm{M}$, however, at 250 and $500 \mu \mathrm{M}$, a red solution was observed, indicating 12 and $24 \%$ hemolysis, respectively.
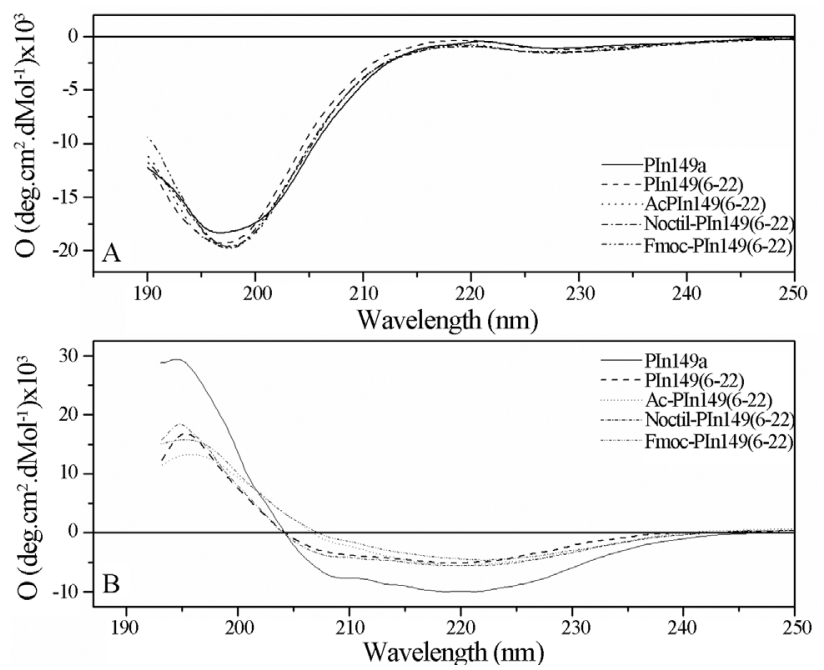

Figure 2 - Far-UV CD spectra of Pln149a analog peptides. (A) Pln149a $(0.1 \mathrm{mg} / \mathrm{mL})$ and the four analogs in aqueous solution. (B) Pln149a and modified analogs in the presence of $1 \mathrm{mM}$ DPPG vesicles. Measurements were taken from 190 to $250 \mathrm{~nm}$ as the average of 8 scans, at $25^{\circ} \mathrm{C}$ and using a $0.1 \mathrm{~cm}$ pathlength quartz cuvette.

\section{Antimicrobial assay}

The antibacterial activity of Pln149a and the four N-terminus modified peptides were directly assessed against Staphylococcus aureus ATCC 25923, and Pseudomonas aeruginosa ATCC 9027. The MIC and MBC (minimum bactericidal concentration) values are presented for each peptide for each microorganism in Table 1.

Pln149a showed stronger antimicrobial activities against Staphylococcus aureus. No bacterial growth was observed in the presence of Pln149a from 78 to $620 \mu \mathrm{M}$. The inhibitory concentrations in which no bacterial growth observed for $P$. aeruginosa were higher than $310 \mu \mathrm{M}$. Pln149a was proved to be lethal for these two microorganisms, none of the aliquots in which inhibition was noted from assay with both strains were capable of resuming growth on agar plates in medium in the absence of Pln149a after $24 \mathrm{~h}$ incubation due to its bactericidal action. However, the analogs (except the Fmoc-analog) presented a different mode of action, promoting a bacteriostatic inhibition against $S$. aureus and $P$. aeruginosa in most of the wells in which growth inhibition was detected.

The Fmoc-analog peptide presented a bactericide activity in the wells with the most elevated concentrations of the peptide $(620$ to $155 \mu \mathrm{M})$ for both Staphylococcus aureus and $P$. aeruginosa.

No growth inhibition was detected against Candida albicans due to the action of Pln149a and analogs.

\section{Leakage assays}

The effects of vesicle perturbation by the presence of each antimicrobial peptide analog to Pln149 were determined by calcein leakage experiments on POPG vesicles. Pln149a and all the four analog peptides showed the capability of promoting the total leakage of calcein from the liposomes. According to Figure 3, the percent of calcein re-

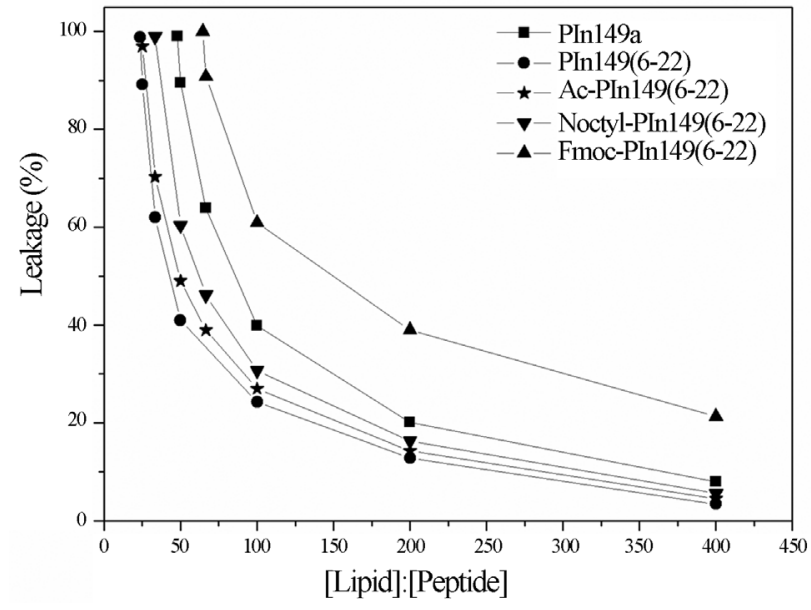

Figure 3 - Leakage action of Pln149a and the four analogs peptides on membrane models. Calcein leakage was promoted by the addition of increasing concentrations of the peptides $(0.25$ to $4 \mu \mathrm{M})$ to LUVs of POPG. $100 \%$ leakage occurred with the addition of Triton X-100. 
leased from the vesicles increased proportionally to the amount of peptide used in the assay, reaching approximately $100 \%$ leakage to the lowest lipid/peptide ratio in cuvette to each analog.

Comparing the curves, once again the Fmoc-analog presented a more accentuated action than the other analogs, which is due to the introduction of the Fmoc moiety in the liposomes acyl chains. However, observing the curves to the other peptides, it was possible to note a higher leakage action of Pln149a compared to the Pln149(6-22) and the other two analogs with the removal of the $5 \mathrm{~N}$-terminus residues. The reduction in leakage action reveals the participation of this segment in the lytic action of Pln149a on the membrane disruption.

\section{Discussion}

The analogs Ac-Pln149(6-22), Noctyl-Pln149(6-22), and Fmoc-Pln149(6-22) presented an increase in hydrophobicity compared to $\operatorname{Pln} 149(6-22)$, that is due to the non-polar character in their N-terminus. Despite the increase of non-polarity, three of these $\mathrm{N}$-terminus modified peptides remained with low level of hemolytic activity. The weak hemolytic effect of Pln149a and analogs in front of the red cell membranes is in agreement with the lack of specificity/binding of Pln149a to zwitterionic phospholipids vesicles. Only the Fmoc-Pln149(6-22) analog presented a more significant hemolytic property in concentrations higher than $250 \mu \mathrm{M}$. Zwitterionic phospholipids, specially the ones from phosphatidylethanolamine series (PE), are also the major component (approximately 89\%) of the Candida cellular membrane (Blondelle et al., 1999), in which no growth inhibition was detected to the action of the Plantaricin 149 analogs.

Taking in account the two analogs Pln149a and Pln149(6-22), in which the difference is due to the 5 first $\mathrm{N}$-terminus residues on the former, it can be noted an increase in the MIC to the Staphylococcus aureus due to the pentapeptide removal, this reduction in antimicrobial activity is in agreement with the decrease in leakage assays observed for Pln149(6-22), that reveals a role for this region of the antimicrobial peptide in its antibacterial activity. The typical conformational change from random structure to helical element, observed in CD studies for these two analogs, revealed that the steps of electrostatic attraction and the helix stabilization in the antimicrobial peptide binding to the liposomes does still remain on these peptides. However, the reduction of Pln149a size resulted in a slightly less appropriated molecule to interact with the liposomes, reducing the magnitude of the helical content induced on the binding, because the presence of the N-terminus pentapeptide (YSLQM) to be in the target membrane must favor the interactions of the amphipathic helix formed in $P \ln 149$ a.
Considering the modifications introduced on the peptides end, they have neither caused severe perturbations on the peptide structure, nor hindered the interaction of these peptides with negative biomembranes, however no increase in the peptide antimicrobial activity was observed for the analogs in which an acetyl or N-octyl were attached at the N-terminus. In Noctyl-Pln149(6-22), despite of the increase of the hydrophobic of the peptide due to the attachment of the acyl chain at the N-terminal end, the effect of disturbing the integrity of both the phospholipid vesicles and the bacterial and/or erythrocyte membranes was not significantly changed. For Noctyl-Pln149(6-22), the incorporation of the acyl chain into the membranes did not severely changed the phospholipid packing which could promote the rupture of the membrane more effectively of that observed to Pln149(6-22), the analog lacking the lipid modification. Indeed, the use of fat acids to promote the lipidation as a general method for increasing the peptide membraneperturbing activity has been questionable (Gatto et al., 2006), since the final effect of the modified peptide tend to be balanced between two opposite effects: the increase of the affinity for the membrane phase, but at the same time, it also makes favourable the peptide aggregation in water, reducing the effective monomer concentration. This inability of the acyl-analog peptides to alter the Pln149 antimicrobial activity indicates that a hydrocarbon chain can not completely fulfill the requirements for the interaction of the peptide with the membrane, suggesting that the hydrophobic environment of the biomembrane inner, created by the phospholipids acyl chains, is not the most appropriated environment to accommodate this region of Pln149a, but this instead the N-terminus pentapeptide must be located at the lipid interface of the bacterial membrane, a region that shares hydrophilic and hydrophobic features.

Conversely, in the analog with the 9-fluorenylmethyloxycarbonyl (Fmoc) moiety modification at the $\mathrm{N}$-terminal end, the disturbing effect of the peptide on biologic membranes was remarkably enhanced. Differently from the other Plantaricin149-analogs, the Fmoc version did not required a negative density of charge to incorporate on the membrane, as observed by its hemolytic properties in concentrations above $125 \mu \mathrm{M}$. In the absence of an electrostatic interaction to attract the peptide to the membrane surface, the high partition coefficient of the fluorene group, which is used as a fluorescent probe in several membrane studies (Azzi, 1975), has driven the binding to the membrane, promoting the incorporation of the hydrophobic Fmoc moiety among the phospholipid layers and significantly altering the integrity of the lipids layers. The Fmocanalogue promoted a significant decrease in the MIC especially to the Gram-negative bacteria, which present a major composition of lipopolysaccharides in the external membrane and lipids of zwitterionic character.

Pln149a antimicrobial activity showed to be more effective against Gram-positive bacteria, a feature that is 
shared with many amphibian antimicrobial peptides (Tagg et al., 1976) that present lowest MIC values to Staphylococcus, Listeria. The difference in the bactericide/bacteriostatic mechanism of action of Pln149a and Pln149(6-22) can be attributed to the removal of the $\mathrm{N}$-terminus residues in the latter, because this region must play a secondary role in the peptide adsorption on the liposomes. Besides, the other analogs (except the Fmoc-analog) presented higher MICs values than Pln149a, confirming the importance of the contribution from the N-terminus segment to Pln149 lytic activity at biologic membranes.

Interestingly, the Fmoc-Pln149(6-22) were more active against Pseudomonas aeruginosa growth and, although the reduction of the peptide size, the presence of this highly hydrophobic group at this position conferred to the analog a higher inhibitory property against this bacteria.

Additional findings could be included in the proposed model for the Pln149a mechanism of action (Lpes et al., 2009). Reducing the non-polar character of Pln149a, by the removal of the first $5 \mathrm{~N}$-terminus residues, does not annul its antimicrobial property, given that some steps of the binding to the negative liposome were still retained (the electrostatic attraction, the induction of the amphipathic helix and the adsorption of the helical element between the phospholipid polar heads). The occurrence of these steps resulted in a growth delay for the two bacteria tested. Nonetheless, the absence of a peptide region to be introduced in the lipid-aqueous interface can remove the lethal action of this peptide.

\section{Acknowledgments}

We are grateful to Prof G. Tonarelli for supervisioning peptide synthesis, Prof. H.S.S. Araújo and Prof. J.C. Rosa for primary structure sequencing and mass spectroscopy analysis, respectively. This work was supported by FAPESP (CEPID program), and in part by research grant 573607/2008-7 (INCT, INBEQMeDI program from CNPq, FAPESP and the Ministry of Health).

\section{References}

Azzi A (1975) The application of fluorescent probes in membrane studies. Q Rev Biophys 8:237-316.

Blondelle SE, Lohner K, Aguilar MI (1999) Lipid-induced conformation and lipid-binding properties of cytolytic and antimicrobial peptides: determination and biological specifity. Biochim Biophys Acta 1462:89-108.

Boman HG (1995) Peptide antibiotics and their role in innate immunity. Annu Rev Immunol 13:61-92.

Castro MS, Ferreira TCG, Cilli EM, Crusca Jr E, Mendes-Giannini MJS, Sebben A, Ricart CAO, Sousa MV, Fontes W (2009) Hylin a1, the first cytolytic peptide isolated from the arboreal South American frog Hypsiboas albopunctatus ("spotted treefrog"). Peptides 30:291-296.

Gatto E, Mazzuca C, Stella L, Venanzi M, Toniolo C, Pispisa B (2006) Effect of peptide lipidation on membrane perturbing activity: a comparative study on two trichogin analogues. J Phys Chem B 110:22813-22818.

Gong T, Li W, Wang Y, Jiang Y, Zhang Q, Feng W, Jiang Z, Li M (2011) Expression of mouse beta defensin 2 in Escherichia coli and its broad-spectrum antimicrobial activity. Braz J Microbiol 42:1180-1187.

Gordon YJ, Romanowski EG (2005) A Review of Antimicrobial Peptides and Their Therapeutic Potential as Anti-Infective Drugs. Curr Eye Res 30:505-515.

Kato T, Matsuda T, Ogawa E, Ogawa H, Kato H, Doi U, Nakamura R (1994) Plantaricin-149, a bacteriocin produced by Lactobacillus plantarum NRIC 149. J Ferment Bioeng 77:277-282.

Koo YS, Kim JM, Park IY, Yu BJ, Jang SA, Kim KS, Park CB, Cho JH, Kim SC (2008) Structure-activity relations of parasin I, a histone H2A-derived antimicrobial peptide. Peptides 2:1102-1108.

Kristiansen PE, Fimland G, Mantzilas D, Nissen-Meyer J (2005) Structure and Mode of Action of the Membrane-permeabilizing Antimicrobial Peptide Pheromone Plantaricin A. J Biol Chem 280:22945-22950.

Leite JRSA, Brand GD, Silva LP, Kückelhaus SAS, Bento WRC, Araújo ALT, Martins GR Lazzari AM, Bloch Jr C (2008) Dermaseptins from Phyllomedusa oreades and Phyllomedusa distincta: Secondary structure, antimicrobial activity, and mammalian cell toxicity. Comp Biochem Phys A 151:336-343.

Lopes JLS, Nobre TM, Siano A, Humpola V, Bossolan NRS, Zaniquelli MED, Tonarelli G, Beltramini LM (2009) Disruption of Saccharomyces cerevisiae by Plantaricin 149 and investigation of its mechanism of action with biomembrane model systems. Biochim Biophys Acta 1788:2252-2258.

Marshall SH, Arenas G (2003) Antimicrobial peptides: A natural alternative to chemical antibiotics and a potential for applied biotechnology. Electron J Biotechno 6.

McClare CW (1971) An accurate and convenient organic phosphorus assay. Anal Biochem 39:527-530.

McKay LL, Baldwin KA (1990) Applications for biotechnology: present and future improvements in lactic acid bacteria: A review. FEMS Microbiol Rev 7:3-14.

Müller DM, Carrasco MS, Simonetta AC, Beltramini LM, Tonarelli GG (2007) A synthetic analog of Plantaricin 149 inhibiting food-borne pathogenic bacteria: evidence for $\alpha$-helical conformation involved in bacteria-membrane interaction. J Pept Sci 13:171-178.

Nikaido H (2009) Multidrug Resistance in Bacteria. Ann Rev Biochem 78:119-146.

Sato H, Feix JB (2006) Peptide-membrane interactions and mechanisms of membrane destruction by amphipathic $\alpha$-helical antimicrobial peptides. Biochim Biophys Acta 1758:12451256.

Tagg JR, Dajani AS, Wannamaker LW (1976) Bacteriocins of Gram-positive bacteria. Bacteriol Rev 40:722-756.

Toke O (2005) Antimicrobial peptides: new candidates in the fight against bacterial infections. Biopolymers 80:717-735.

Tsuberya H, Ofek I, Cohen S, Fridkin M (2001) N-terminal modifications of Polymyxin B nonapeptide and their effect on antibacterial activity. Peptides 22:1675-1681.

Wayne PA (1999) NCCLS: National Committee For Clinical Laboratory Standards. Performance. Standards for Antimicrobial Susceptibility Testing. 4th ed. 
Yeaman MR, Yount NY (2003) Mechanisms of antimicrobial peptide action and resistance. Pharmacol Rev 55:27-55.

Zavisic G, Petricevic S, Radulovic Z, Begovic J, Golic N, Topisirovic L, Strahinic I (2012) Probiotic features of two oral Lactobacillus isolates. Braz J Microbiol 43:418-428.
Zhao H, Sood R, Jutila A, Bose S, Fimland G, Nissen-Meyer J, Kinnunen PK (2006) Interaction of the antimicrobial peptide pheromone Plantaricin A with model membranes: implications for a novel mechanism of action. Biochim Biophys Acta 1758:1461-74.

All the content of the journal, except where otherwise noted, is licensed under a Creative Commons License CC BY-NC 